\title{
Causality of Product Awareness Coconut Flour Towards Future Engagement, Indonesian Market
}

\author{
Leonnard Ong ${ }^{1 *}$, Elvina ${ }^{2}$, Gabriella Rosellinny ${ }^{3}$, \\ Jonathan Augustinus ${ }^{4}$, Novia Rianti ${ }^{5}$ \\ ${ }^{12345}$ Sekolah Tinggi Manajemen Ipmi, DKI Jakarta 12750, Indonesia
}

\begin{abstract}
A B S T R A C T
In order to establish a future engagement of Indonesian market in terms of coconut flour, awareness of the product is needed for the consumer decision making to purchase the product which will lead to future engagement. This study aims to examine the effects of product and awareness and consumer decision making towards future engagement in Indonesia. By employing SmartPLS, we prove that existence of product has a relatively strong negative relationship with awareness (.55); while awareness has a relatively weak relationship with consumer decision making to purchase a product (.37) and the decision made by customer to purchase healthy product have a relatively strong positive relationship towards engagement of the product in the future (.66). Further implications are discussed.
\end{abstract}

\section{ART I CLE INF O}

Product, Awareness, Consumer Decision Making, Future Engagement, SmartPLS.
*Correspondent Email:

leonnard.ong@ipmi.ac.id

Copyright (C) 2018 Authors. This is an open access article distributed under the Creative Commons Attribution License, which permits unrestricted use, distribution, and reproduction in any medium, provided the original work is properly cited.

\section{INTRODUCTION}

Flour is a powdery substance which is created through a milling process. It is usually made by grinding grains such as rice, oats, corn, wheat, maize, rye, barley, etc. As one of the main ingredients in making bread, cake, cookies, etc., flour is one the most common and sought-after ingredients in the world. In 2015, the global market of flour was valued at US $\$ 200,297$ million. By the year 2020, it is expected to grow into $\$ 270,895$ million with a forecast of $4.4 \%$ Compound Annual Growth Rate (CAGR) throughout the period. In 2022 it is predicted that awareness about gluten-free products is the most impacting factor to the global flour market (Satsangi, 2016). People around the world are starting to demand for healthier products (Nielsen, 2016).

In Indonesia, flour is one of the most popular primary needs that can be seen in everyday life. From home industry, factory, and other things, flour gives benefits to the user by giving a good texture, aroma, looks, taste, and so on for the users to enjoy. For home industry in Indonesia, flour could be used for almost all purposes in cooking depending 
on the flour type. It can be used for frying, baking, grilling, steaming, as a media to thicken sauces and many other creative ideas in terms of using flour in cooking. However, there are also disadvantages in using and consuming flour. Flour typically has a high carbohydrate contribution as an ingredient in cooking. Since carbohydrates will be converted into sugar when digested in the human body, it might cause diabetes, heart attack, and other diseases when flour is consumed excessively. Wheat flour that contains gluten is one of the most dominating products in Indonesian flour market; it covers more than half of the market. Indonesia itself is not excluded from the global countries that are shifting to healthier products and lifestyles. According to a Global Marketing Intelligence Firm named Mintel (2017), majority of Indonesian urbanites, which resided in Jakarta, Bandung, Surabaya, Yogyakarta and Semarang are eating healthier and exercising more. $75 \%$ of Indonesians living in the urban areas aim and demand to have a healthier diet while 58\% wanted to exercise in order to maintain their fitness level. Approximately $41 \%$ of urban Indonesians decided to avoid refined sugar and consume more fruits and vegetables related products.

Coconut flour is one of the gluten free flour that is present and still not well known in Indonesia. It is made by processing dried coconut flesh until it was shredded to different levels of smoothness to be called as coconut flour. Dried coconut flesh could be obtained by firstly processing the coconut flesh to coconut milk and the leftovers of it would be baked at a low temperature in order for the flesh to dry and easily crushed into flour. When used as an ingredient for cooking or baking, coconut flour gives a strong aroma and coconut flavor to food and baked goods. Like any other gluten-free flour, it is also an alternative to wheat flour or other gluten flours. Coconut flour have several benefits for health such as helping consumer to control their weigh, reducing total cholesterol in the blood, preventing constipation, and maintain digestive system in order to be healthier. With those benefits, as one of the top producer of coconut, Indonesia has been exporting the product outside Indonesia while in Indonesia itself people rarely experience the benefit from the coconut flour.
In this study, we investigate the role of product awareness towards the future engagement of the product; conceptually on the relationship between product, awareness, consumer decision making, and future engagement. Our study focuses on 25 years old and above health conscious people in Jakarta which will represent Indonesia with socio economic status of class A \& B. This study employs SmartPLS to examine the effects of individual variables on outcome variables. The rest of this paper is structured as follows. Review of the literature on product, awareness, consumer decision making, and future engagement. After that will be discussed methods and discussions of the results as well as conclusion and recommendation.

\section{BACKGROUND AND HYPOTHESES Product and Awareness}

Product can further be dissected into three levels. As the level of product goes up, more values are added into it. This is not only to better satisfy the market but also to differentiate one product from another as it defines the product's segment, target and position and proposed a reason on why to buy this particular product. These three levels are the core product, the actual product and the augmented product (Kotler and Armstrong, 2012).

In the world of marketing, awareness is the power and force of the brand's presence in the consumer's mind (Aaker, 1996). Awareness could be measured by how customers or consumers keep in mind about brand and how they recall the brand from a certain category of products. Awareness has been suggested to be measured through perception (Eriksen, 1960; Holender, 1986). Perception is a conscious state of mind that can affect awareness. For example, one check that some branded products are expensive (perceived) then one will be aware of the expensive prices of branded products. Awareness will determine the customer choice in choosing the product or services from the whole market.

H1: The existence of product (coconut flour) does not necessarily affect awareness. 


\section{Decision Making and Future Engagement}

The product awareness of coconut flour affects the decision making of consumer to purchase the coconut flour. In addition to this, for the long term, the engagement of Indonesian consumer towards coconut flour may also be affected. Van Doorn et al. (2010) define customer engagement as a customer's behavioral manifestations that have a brand or a firm focus, beyond purchase, resulting from motivational drivers.

Bowden (2009) defines customer engagement as "a psychological process that models the underlying mechanisms by which customer loyalty forms for new customers of a service brand as well as the mechanisms by which loyalty may be maintained for repeat purchase customers of a service brand." In order for the coconut flour purchase to be continuous and sustainable in the future, consumers must be engaged to the product itself and for that to happen, trust and loyalty must be present. However, trust and loyalty will not be present if there is little to no effort of product awareness in the first place and careful planning on engaging consumers.

The customer engagement concept explained that when the products and services are introduced, it will create marketing activities to create an awareness which helps to identify the customers' needs for the product and services. Once customer makes purchase. It will create an experience for the customers. When customer has a positive experience with the products. They would be satisfied with the firm and it will create repeat purchase.

$\mathbf{H}_{3}$ : The decision made by customer to purchase healthy product (coconut flour) affects the engagement of the product in the future.

Based on the hypotheses above, we are able to build and form a conceptual framework of this study. Figure 1 below shows the conceptual framework of this study.

\section{METHODOLOGY}

\section{Measurement Development}

There are four main indicators that could be seen from the research framework, they are Product, Awareness, Consumer Decision Making and Future Engagement. Product will depend on core product, actual product, and the augmented product based on the three levels of products mentioned in the literature review while awareness will depend on the knowledge and the perception of the consumers towards the product itself since knowledge and perception are the indicators whether a consumer is aware or not aware of the product, in this case is the coconut flour. In terms of consumer decision making, it is dependent on consumers' culture, social, personal and psychological which are consumer purchase behaviors that will then lead the consumers to find, try or buy the product.

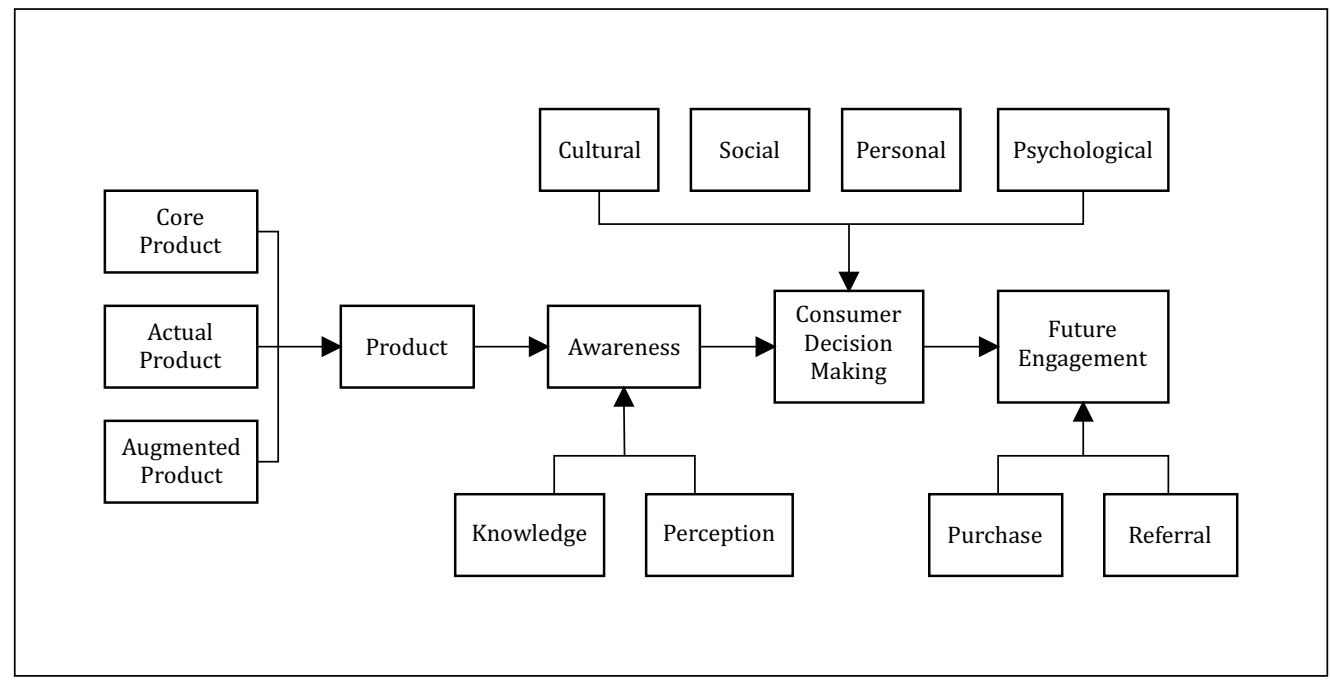

Figure 1. Conceptual Framework 
In the end, the future engagement of this particular product towards the market will depend on the decision made by the consumers on whether to purchase or not to purchase the product, which is no other than the coconut flour. Future Engagement has also two factors which are feedbacks and referrals from the consumers of the coconut flour. The relationship between the variables in the research framework will be tested.

\section{Sample and Data Collection}

A survey with a five-point Likert scale is used to measure the indicators stated in the framework. Data were collected to health-conscious people age 25 and above who live in Jakarta. The total 150 samples were collected using the non-probabilistic method with the convenience sampling. Data analysis was carried out by using Smart PLS.

\section{RESULTS}

\section{Reliability and Validity Test}

This survey will undergo a pilot test to 20 respondents that matches the criteria given. this pilot test is needed as to know whether the survey questionnaires are easily understood, clearly articulated (not biased) and engaged the same perception for each question given so that respondents can give the correct responds that will be very much useful for the study. The data will then be check for its reliability and validity presented by the Cronbach's alpha. The acceptable value of alpha is ranging from 0.70 to 0.95 , which means that the items are correlated to each other (Tavakol \& Dennick, 2011). Table 1 shows the result of the reliability and validity test of this study.

Table 1. Reliability and Validity Test Result

\begin{tabular}{|c|c|}
\hline Variable & Cronbach's Alpha \\
\hline Product & 0.818 \\
\hline Awareness & 0.778 \\
\hline Consumer Decision Making & 0.859 \\
\hline Future Engagement & 0.880 \\
\hline
\end{tabular}

Knowing that the Cronbach's Alpha for each variable are above 0.7 , the researchers could continue to give the questionnaires to the rest of the respondents (130 target respondents) since the questions that represent each variable are both reliable and valid.

\section{Hypotheses Testing}

H1: The existence of product does not necessarily affect awareness.

The regression of product, which is denoted as X, and awareness, which is denoted as $\mathrm{Y}$, is shown to be 0.550 . This means that there is a relatively strong negative relationship between the latent variable product and awareness which makes the hypothesis true. So therefore, the existence of product does not necessarily affect awareness. There must be additional effort or inputs in order for product (coconut flour) to affect the awareness of the product in Indonesia.

H2: Low product awareness influence the consumer decision making to purchase a product.

The regression of awareness, which is now denoted as $\mathrm{X}$, and consumer decision making, which is denoted as $Y$, is 0.372 . This shows that the relationship between awareness and consumer decision making is not significant or relatively weak which means that the hypothesis is false. It also further concludes that when the market knows a certain product (coconut flour), even to the most in-depth knowledge and great perception, it does mean that the market will purchase the product. There might be other factors that are influencing the market in terms of decision making to purchase this certain product (coconut flour). These other factors might be from indicators such as cultural, social, personal and psychological factors of the customers which made customers to purchase a product that is suitable to their needs and preferences. For example: personal expectations are not reached, or the surroundings of the customers do not support the decision to purchase the product.

H3: The decision made by customer to purchase healthy product affects the engagement of the product in the future.

The regression of consumer decision making, which 
is denoted as $\mathrm{X}$, and future engagement, which is denoted as $\mathrm{Y}$, is shown to be 0.661 . This means that there is a relatively strong positive relationship between consumer decision making and future engagement thus, making the hypothesis true. Therefore, when customers felt that they are fit or suitable with a certain product, specifically coconut flour, they will purchase the product and has a tendency to re-purchase more in the future. They might regularly purchase to consume, spread a positive word-of mouth or referral to their surroundings, or even share their thoughts and promote the products through their social media. This will certainly affect the engagement of the product (coconut flour) towards the market in the future.

To conclude, there is a relationship between product awareness and future engagement in which shown from the regression results of product to awareness and consumer decision making to future engagement with relatively strong relationship (regression value of product awareness: 0.550; consumer decision making future engagement: 0.661). However, there are other decision-making factors that might affect the customers' decision to purchase in which shown from the relatively weak relationship between awareness and consumer decision making, which is shown with a regression value of 0.372 . Table 2 shows the path coefficient of the variables.

Table 2. Path Coefficient of the Variables

\begin{tabular}{c|cccc}
\hline & Awareness & CDM & FE & Product \\
\hline Awareness & - & 0.372 & - & - \\
CDM & - & - & 0,661 & - \\
FE & - & - & - & - \\
Product & 0,550 & - & - & - \\
\hline
\end{tabular}

\section{DISCUSSIONS}

Based on the findings of this study, it is understood that the existence of the product itself, no matter how beneficial it is, does not necessarily affect the awareness of the market (H1 $\mathbf{H}_{1}$ accepted). So, in order for the product to be known in the market, there must be an effort needed to be done. However, on the consumer decision making side, awareness does not play a big role in pushing the consumers to make a purchase of the product $\left(\mathbf{H}_{2}\right.$ rejected). There might be other variables that play a bigger role comparing to awareness in terms of influencing consumers to buy a certain product, here is coconut flour. Lastly, there is a relationship between consumer decision making and the engagement of

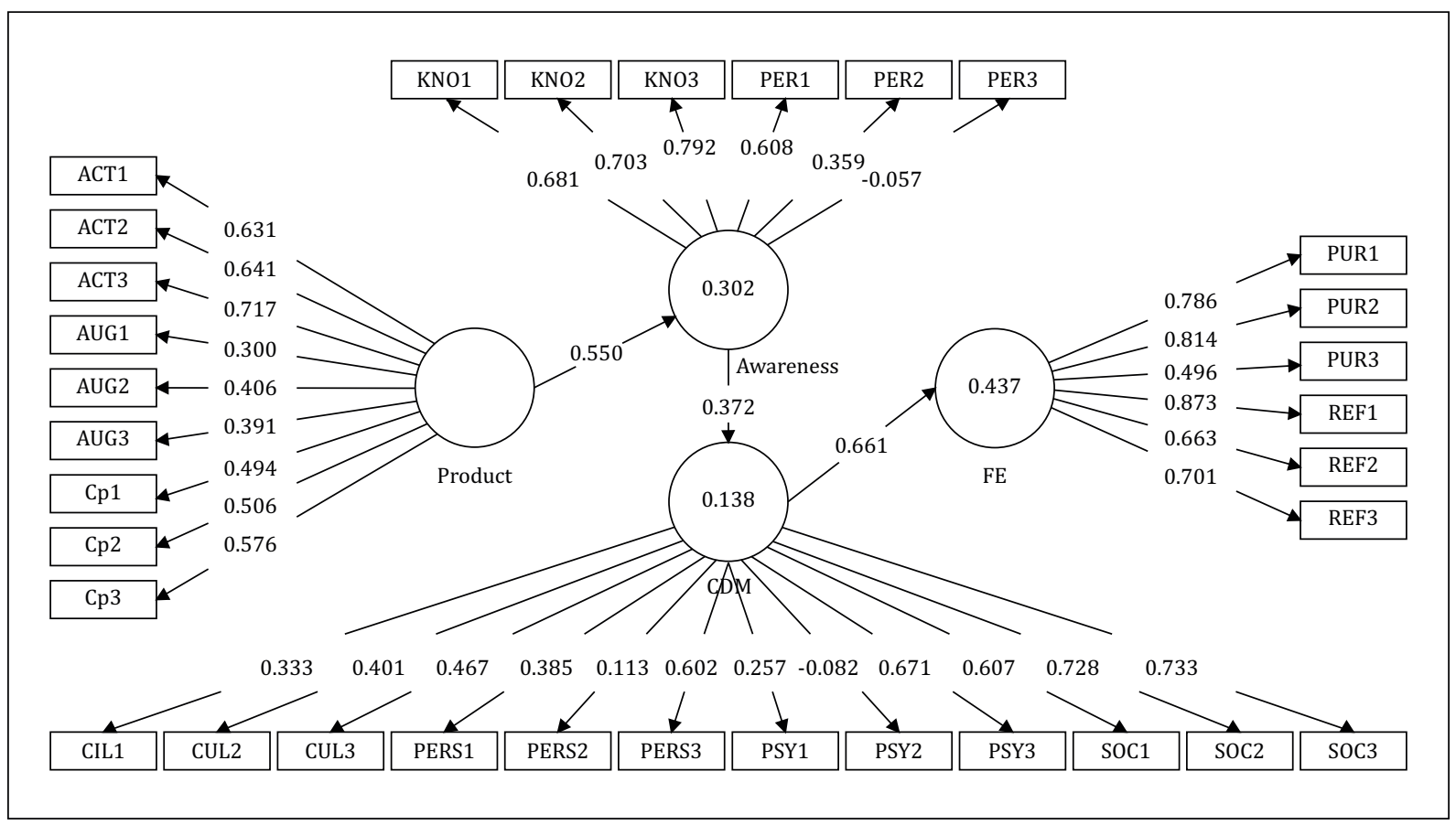

Figure 2. Research Output Diagram 
consumer in the future (H3 accepted). So, with this information, important to be reminded that for the sustainability and continuality of purchase and consumers-to-consumers interactions, there should be a decision to make the first purchase as the kick start of the product to consumer relationship to form and bloom.

\section{CONCLUSION, LIMITATION AND FUTURE RESEARCH}

With this study, it is hoped that there is more understanding in terms of the present awareness of coconut flour in the Indonesian market and how to better approach the market to purchase the product, which is none other than the coconut flour itself.

To conclude, there is an overall relationship between product awareness and future engagement which can be seen from the relatively strong relationship between product and awareness (negatively) and consumer decision making and future engagement (positively). However, there are other decision-making factors that might affect the consumers' decision to purchase a certain product since it is shown that awareness has a relatively weak relationship towards the decision making of consumers. That is why, there is a need of future research in order to identify the right variable that has a relatively strong relationship towards the consumer decision making variable. Also, future research can also expand the research into other big cities in Indonesia since this research is only conducted in the capital city of Indonesia as a representative.

\section{REFEREN CES}

Aaker, D.A. (1996). Building strong brands. New York: Free Press.

Bowden, J. L. H. (2009). The process of customer engagement: A conceptual framework. Journal of Marketing Theory and Practice, 17(1), 63-74.

Eriksen, C. W. (1960). Discrimination and learning without awareness: a methodological survey and evaluation. Psychological review, 67(5), 279-300.doi: 10.1037/h0041622

Holender, D. (1986). Semantic activation without conscious identification in dichotic listening, parafoveal vision, and visual masking: A survey and appraisal. Behavioral and brain Sciences, 9(1), 1-23.doi: $10.1017 / \mathrm{S} 0140525 \times 00021269$

Kotler, P., \& Keller, K. (2012). Marketing Management 14e. Boston, Mass.: Prentice Hall/Pearson.

Macdonald, E. K., \& Sharp, B. M. (2000). Brand awareness effects on consumer decision making for a common, repeat purchase product:: A replication. Journal of business research, 48(1), 5-15.

Mintel Press Team. (2017). Healthy lifestyles a growing focus for consumers in Southeast Asia. Mintel. Retrieved December 2017 from http://www.mintel.com/press-centre/social-and-lifestyle/healthy-lifestylesgrowing-focus-for-southeast-asians

Nielsen. (2016). What's in our food and on our mind ingredient and dining-out trends around the world. Retrieved from http://www.nielsen.com/content/dam/nielsenglobal/eu/docs/pdf/Global\%20Ingredient\%20 and\%200ut-of-Home\%20Dining\%20Trends\%20Report\%20FINAL\%20(1).pdf

Tavakol, M., \&Dennick, R. (2011). Making sense of Cronbach's alpha. International Journal of Medical Education, 2, 53-55. http://dx.doi.org/10.5116/ijme.4dfb.8dfd 
Satsangi, S. (2016). Flour Market by Raw Material (Wheat, Rice, Maize, and Others), Application (Bread \& Bakery Products; Noodles \& Pasta; Animal Feed; Wafers, Crackers, \& Biscuits; Non-Food Application; and Others), Technology (Dry Technology and Wet Technology) - Global Opportunity Analysis and Industry Forecast, 2014-2022. Allied Market Research. Retrieved from https://www.alliedmarketresearch.com/flour-market

Tavakol, M., \&Dennick, R. (2011). Making sense of Cronbach's alpha. International Journal of Medical Education, 2, 53-55. http://dx.doi.org/10.5116/ijme.4dfb.8dfd

Van Doorn, J., Lemon, K., Mittal, V., Nass, S., Pick, D., Pirner, P., \&Verhoef, P. (2010). Customer engagement behavior: Theoretical foundations and research directions. Journal of Service Research, 13(3), 253-266. 